University of Nebraska - Lincoln

DigitalCommons@University of Nebraska - Lincoln

Sociology Department, Faculty Publications

Sociology, Department of

$7-2010$

Experienced and vicarious victimization: Do social support and self-esteem prevent delinquent responses?

Lisa A. Kort-Butler

University of Nebraska-Lincoln, Ikortbutler2@unl.edu

Follow this and additional works at: https://digitalcommons.unl.edu/sociologyfacpub

Part of the Criminology Commons

Kort-Butler, Lisa A., "Experienced and vicarious victimization: Do social support and self-esteem prevent delinquent responses?" (2010). Sociology Department, Faculty Publications. 192.

https://digitalcommons.unl.edu/sociologyfacpub/192

This Article is brought to you for free and open access by the Sociology, Department of at DigitalCommons@University of Nebraska - Lincoln. It has been accepted for inclusion in Sociology Department, Faculty Publications by an authorized administrator of DigitalCommons@University of Nebraska - Lincoln. 


\title{
Experienced and vicarious victimization: Do social support and self-esteem prevent delinquent responses?
}

\author{
Lisa A. Kort-Butler \\ Department of Sociology, 711 Oldfather Hall, P.O. Box 880324, University of Nebraska-Lincoln, \\ Lincoln, NE 68588-0324 USA; tel 402472 6005, fax 402472 6070, email lkortbutler2@unl.edu
}

\begin{abstract}
This article extended research that views violent victimization as a stressor that may lead to delinquency. Following general strain theory, the analysis considered the mediating role of fearfulness, depression, and anxiety. The analysis also examined whether social support and self-esteem conditioned the relationship between victimization and delinquency. Results indicated that negative emotions did not substantially mediate the effect of victimization on delinquency. Among those with lower levels of both social support and self-esteem, experiencing violent victimization and witnessing victimization led to general delinquency. Victimization was unrelated to general delinquency among those with higher levels of both these resources. Experiencing victimization led to violent delinquency for all groups. Witnessing victimization and perceiving an unsafe neighborhood led to violent delinquency only among those with lower levels of both resources. Additionally, negative emotions and a bad temper led to violent delinquency only for those low in resources. The results suggested that fostering social support networks and self-esteem among adolescents victimized by violence can limit delinquency.
\end{abstract}

\section{Introduction}

Adolescents are disproportionately victimized by violent offenses. According to the National Center for Injury Prevention and Control, in 2006 homicide was the second leading cause of death for fifteen to nineteen year olds and the third leading cause of death for ten to fourteen year olds (Centers for Disease Control, 2010). The 2006 National Crime Victimization Survey found that sixteen to nineteen year olds had the highest rate of violent victimization $(52.3$ per 1,000$)$, followed by twelve to fifteen year olds $(47.3$ per 1,000$)$ (Rand \& Catalano, 2007). On average between 1993 and 2003, adolescents aged twelve to seventeen were two and a half times more likely than adults to be victims of nonfatal violent crimes (Snyder \& Sickmund, 2006.) Victimization during adolescence is linked to later problems, including future victimization, mental health problems, illegal behaviors, and drug use (Fagan, 2003; Haynie et al., 2009; Macmillan, 2001; Menard, 2002; Schwab-Stone et al., 1999; Singer et al., 1995).

Three basic lines of research explore the link between victimization and delinquency (Cuevas, Finkelhor, Turner, \& Omrod, 2007). First, research has noted a link between childhood abuse and later delinquency (e.g., Brezina, 1998; Widom, 1989). In this literature, abuse and later delinquency are linked theoretically by behavioral modeling or the destruction of the parent-child bond. Second, research has explored the relationship between adolescent victimization and delinquency, fo- cusing on how involvement in delinquency or relationships with delinquent peers increase risk for victimization (e.g., Fagan \& Mazerolle, 2008; Lauritsen et al., 1991). In this view, adolescents' lifestyles or routine activities are theorized to put them at risk for both victimization and delinquency. A third line of research has explored victimization as a social psychological strain. According to general strain theory (GST), victimization can act as a stressor that contributes to delinquent outcomes as an adolescent tries to cope with the negative experience (Agnew, 2002).

Evidence indicates the viability of a general strain interpretation, in that victimization contributes to later delinquency, controlling for the adolescent's prior delinquent involvement (Hay \& Evans, 2006; Ostrowsky \& Messner, 2005). If adolescent victimization is a factor in later delinquency, then a general strain interpretation provides an avenue for understanding how to mitigate the negative consequences of victimization, namely through enhancing coping resources like social support and self-esteem (Agnew, 2006). Accordingly, this study extended research that views violent victimization - experienced, witnessed, and anticipated - as a stressor that may lead to delinquency in general, and violent delinquency in particular. Following GST, the analyses considered the mediating role of negative emotions, including fearfulness, depression, and anxiety. Further, the analyses examined whether social support and self-esteem acted as potential conditioning factors, inhibiting delinquent responses to victimization. 


\section{General strain theory and victimization}

GST posits that stress has several sources, included the blockage of valued goals, removal of positive stimuli, and the presence of negative stimuli (Agnew, 1992). The experience of stress engenders negative emotions, including anger, anxiety, depression, fear, and frustration. Coping with stress and the associated negative emotions may take legitimate and illegitimate forms, depending on several conditioning factors, including availability of legitimate and illegitimate opportunities, the presence of delinquent peers, prior learning of prosocial or delinquent attitudes, social support, and personal resources like self-esteem, mastery, and coping skills.

Of particular interest in this article is social support and self-esteem. Social support is commonly defined as a resource drawn from others, like family members and friends, who can provide instrumental or emotional assistance to the individual (Thoits, 1995). Conventional social support networks can provide individuals shelter from negative experiences, promote prosocial adaptations, and facilitate legitimate coping responses to strain (Agnew, 1992; Capowich et al., 2001; Cullen, 1994; Cullen et al., 1999). Self-esteem can also help individuals cope with stressful experiences. A strong sense of self-esteem may help individuals be more resilient to the negative qualities of strain, including both negative implications for the self and the emotional consequences of the stressful experience (Thoits, 1995; Turner and Roszell, 1994). Like social support, self-esteem may facilitate legitimate coping efforts (Agnew, 1992; Hoffman \& Cerbone, 1999). Additionally, social support and self-esteem can be reciprocal, in that feeling supported by others contributes to a more positive self-esteem, and self-esteem influences one's perception of support (R. J. Turner \& Turner, 1999). Those with high levels of both resources may be in the best position to manage the potentially damaging effects of strain and engage in legitimate coping.

The basic propositions of GST are supported by research. Stress in various forms predicts delinquent outcomes, and anger in particular appears to mediate the relationship between strain and more aggressive forms of delinquency (e.g., Agnew \& White, 1992; Aseltine et al., 2000; Broidy, 2001; Mazerolle et al., 2000; Mazerolle \& Piquero, 1998; Paternoster \& Mazerolle, 1994). Evidence for the role of the conditioning factors of resources such as social support and self-esteem is more equivocal. Although some studies have demonstrated moderate support for the influence of social support or self-esteem in the strain-delinquency relationship (Bao et al., 2007; Baron, 2007; Robbers, 2004), many studies have found little to no support for these conditional relationships (Capowich et al., 2001; Hoffman \& Cerbone, 1999; Hoffman \& Miller, 1998; Jang, 2007; Jang \& Johnson, 2003; Morash \& Moon, 2007; Paternoster \& Mazerolle, 1994; Tittle et al., 2008).

In a revision of GST, Agnew (2001) described why certain types of strains are more likely to lead to delinquent outcomes. First, when the individual views the strain as unjust, the experience is more likely to provoke emotions that promote criminal reactions. Second, when the individual experiences strain as high in magnitude or severity, it may impede legitimate coping, reduce the perceived costs of a criminal response, and influence one's disposition to engage in crime. Third, when the individual experiences strain that is also associated with low social control, it may reduce the perceived costs of illegitimate coping, but also distance the individual from resources that promote legitimate coping. Finally, the experience of strain may create pressure to cope in a criminal fashion, by limiting the availability of legitimate coping options, or by modeling or reinforcing criminal attitudes and responses to strain.

According to Agnew (2001), criminal victimization meets each of these conditions, making it a type of strain likely to lead to a criminal response. The experience of criminal victimization, particularly of a physical nature, is likely to be viewed as unjust and severe, as well as be associated with low social control and exposure to models for illegitimate coping. Agnew (2002) also argued that vicarious forms of victimization, such as witnessing or learning about victimization that happens to others and anticipating that one will be criminally victimized, are forms of strain that may lead to criminal responses. Witnessing victimization, especially if it happens to someone close to the witness, if it happens in a social setting the witness frequents (like school or neighborhood), or if the event is unsuccessfully resolved, can engender negative emotions in the individual. Attempting to cope with these emotions may lead to delinquency, as may a desire for revenge or protection. Witnessing or learning about someone's victimization may also contribute to the individual's experience of anticipated strain. Concern or fear of future victimization future may lead the individual to engage in delinquency to prevent victimization from occurring or to cope with negative emotions.

\section{Exposure to victimization and adolescent well-being}

Research shows that victimization and exposure to violence, particularly in the community, can be detrimental to adolescent well-being. For instance, Rosenthal (2000) found that being victimized and witnessing violence in the community had independent and cumulative effects on adolescent mental health, contributing to anxiety, depression, and anger. In terms of anticipated victimization, Allison, Adalf and Mates (1997) noted that adolescents who were worried about gangs, strangers, and racial tensions turned to substance use. Other studies have demonstrated that personal victimization and exposure to violence in the community are related to psychological problems, suicidal behaviors, aggressiveness, and personal use of violence (Cleary, 2000; Flannery et al., 2001; Moses, 1999; Patchin et al., 2006; Schwab-Stone et al., 1995; Shaffer \& Ruback, 2002; Turner et al., 2006).

Researchers specifically applying GST have examined victimization and exposure to violence as stressors contributing to criminal offending, and provided preliminary analyses regarding the mediating effects of negative emotions and the effects of conditioning factors. First, victimization appears to predict delinquent outcomes, both in general samples and in special populations. Controlling for other negative life events, deviant peers, and prior deviance, Eitle and Turner (2002) found that a history of hearing about others' victimizations, as well as more recent experiences of personal victimization and of witnessing violence in the community contributed to criminal behavior among young adults. Agnew (2002) also discovered that experienced victimization, the victimization experiences of family and friends, and high levels of anticipated victimization contributed to serious delinquency. In a sample of street youth, Baron (2004) found that property victimization predicted total crime, and that violent victimization predicted violent crime. In a Korean sample, Moon, Blurton and McCluskey (2008) noted that criminal victimization was positively related to delinquency. In a sample of incarcerated juveniles, Neff and Waite (2007) found that victimization predicted earlier age of substance use onset among females and recent substance use among males.

Second, negative emotions appear to play a role in the relationship between victimization and delinquency, although there are inconsistencies. Examining the mediating role of anger, Hay and Evans (2006) found that victimization impacted later general and serious delinquency, that anger mediated the relationship between victimization and general delinquency, but that anger did not fully mediate the relationship between victimization and serious delinquency. Examining anger and depression, Piquero and Sealock (2000) noted that the strain of physical and emotional abuse was related to property offending and interpersonal aggression. The effect on interpersonal aggression was marginally mediated by anger, but the relationships were not mediated by depression. Ostrowsky and Messner (2005) de- 
tected a relationship between victimization and both depression and delinquency, but depression did not mediate the relationship between victimization and delinquency. Likewise, Hollist, Hughes and Schaible (2009) described interrelationships among maltreatment, anger, anxiety, depression, and delinquency, yet none of these negative emotions substantially mediated the effect of maltreatment and delinquency.

Finally, like other tests of conditioning effects in GST, initial tests dealing with victimization and personal resources have produced equivocal results. Aceves and Cookston (2007) noted that the quality of the parent-child relationship did buffer the effect of victimization on later violent behavior by the adolescent. In contrast, Hay and Evans (2006) found that attachment to parents did not condition the relationship between victimization and delinquency, but self-control did condition the relationship. Baron (2004) detected interactions between emotional abuse and self-esteem and between violent victimization and self-efficacy on both total crime and violent crime. These interactions were in a direction opposite the prediction: for youth with high levels of self-esteem and self-efficacy, victimization increased, rather than decreased, delinquency.

\section{Hypotheses}

Although research appears to support the view that victimization is a strain that leads to delinquency, support for the mediating effects of negative emotions and for the conditioning effects of personal resources is more evasive. Following the recommendations of Hay and Evans (2006) and Agnew (2002), this study examined the mediating effect of negative emotions, including fearfulness, depression, and anxiety, as well as the role of two conditioning variables proposed in GST, social support and self-esteem.

Hypothesis 1. The experience of violent victimization, witnessing the violent victimization of others, and the anticipation of victimization would contribute to delinquency.

Hypothesis 2. Negative emotions would mediate the relationship between victimization and delinquency. That is, when negative emotions were entered into the model, it was expected that the relationship between victimization and delinquency would be reduced to non-significance.

Hypothesis 3. Social support and self-esteem would condition the relationship between victimization and delinquency. In particular, among adolescents with lower levels of social support and self-esteem, it was expected that victimization would be more likely to result in delinquency.

\section{Data}

The data were from Waves 1 and 2 of the National Longitudinal Study of Adolescent Health (Add Health). Add Health is a nationally representative, probability-based survey of adolescents in grades seven through twelve (Bearman, Jones, \& Udry, 2009). The survey employed a stratified, random sample design of all high schools in the United States. High schools were stratified by region, urbanicity, school size and type, grade span, and percent White and Black. In all, eighty high schools and fiftytwo middle or "feeder" schools were selected with unequal probability of selection. The high schools became the cluster identifier, thus the primary sampling units for participants. For each school sampled, questionnaires were collected from students present on the day of administration. Then, a nationally representative sample of students from the school rosters and from those who completed the in-school questionnaire were selected to participate in the in-home data collection phase. Survey administers used computer-assisted personal interviews and audio computer-assisted self-interviews for sensitive questions. Data for this study were drawn from Wave 1 interviews gathered in late 1994 and 1995, and Wave 2 interviews gathered in 1996. The final sample size was 10,404 after excluding respondents who were no longer in school, who did not live with any parent figure, who were married, and following listwise deletion procedures for missing cases.

\section{Measures}

Measures of demographic characteristics, baseline levels of delinquency, victimization, negative emotions, and social support and self-esteem were drawn from Wave 1 . The dependent variables, general delinquency and violent delinquency, were drawn from Wave 2. Udry (2004) stated that many sources were consulted to develop and construct the Add Health survey, but that no one scale from the literature remained entirely intact. He suggested the use of alpha reliability of scales and principal components factor analysis to validate items in research. Both approaches were employed in constructing items.

\section{Delinquency}

General delinquency was measured with thirteen items covering a variety of activities as reported in the past twelve months $(\alpha=0.80)$. The activities included violent delinquency, property delinquency (e.g., burglary, stealing), nuisance delinquency (e.g., vandalism, being loud or unruly in public places), running away, and selling drugs. The response categories ranged from 0 (never) to 3 (five or more times). The same items were included on the baseline measure of general delinquency. The analyses also specifically examined violent delinquency. Violent delinquency was measured with three items that included involvement in a serious physical fight, using or threatening to use a weapon to get something from someone, and hurting someone enough for that person to require medical care $(\alpha=0.65)$.

\section{Violent victimization}

Experienced violent victimization consisted of a five item scale assessing the extent to which the respondent was a victim of violence in the past year, including being threatened with a knife or gun, being shot, being stabbed, being jumped, and requiring medical attention for injuries sustained in a fight $(\alpha=0.60)$. Witnessing victimization was one item asking how often the respondent witnessed a stabbing or shooting in the past year. For all of these victimization items, response categories ranged from 0 (never) to 2 (more than once). Anticipated victimization was assessed with three different variables. The first variable was one item asking respondents to assess their chances of being killed by age twenty-one, with response categories ranging from 1 (almost no chance) to 5 (almost certain). This item is comparable to the measure used by Agnew (2002) to assess anticipated victimization. The second variable was one item asking respondents how much they agreed with the statement "you feel safe at your school." Response categories ranged from 1 (strongly agree) to 5 (strongly disagree). The third variable was one item asking respondents to answer true (coded 0) or false (coded 1) to the statement "you feel safe in your neighborhood." Unlike Agnew's (2002) measures that tapped fear of violence in neighborhood and school, these items separate concern for safety from the emotional reaction this concern could generate. As such, these items more directly assess anticipated victimization.

Approximately 25 percent of the sample reported being personally victimized by violence, 11 percent reported witnessing victimization, 15 percent felt they had a " $50 / 50$ " chance or worse of being killed by age twenty-one, 13 percent disagreed or strongly disagreed that they felt safe in school, and 11 percent felt unsafe in their neighborhood. Due to their positive skew, each of these variables was dichotomized. For 
both personal victimization and witnessing victimization, responses were coded 0 if the respondent had not experienced victimization and coded 1 if they had. For being killed by twenty-one, responses were coded 1 if the respondent felt a " $50 / 50$ " chance or greater of being killed, and 0 for other responses. Finally, for perceptions of school safety, respondents were coded one if the respondent disagreed or strongly disagreed, and zero for other responses.

\section{Social support and self-esteem}

The general social support measure was a four-item mean scale assessing the degree to which adolescents feel people in their lives care about them, including teachers, parents, other adults, and friends, with response categories ranging from 1 (not at all) to 5 (very much) ( $\alpha=0.64)$. The measure is consistent with research indicating the perception or belief that support is available, particularly emotional support, is more important for well-being than the actual receipt of support (Pearlin, 1989; Thoits, 1995; Turner \& Lloyd, 1999). Self-esteem was assessed with a six-item mean scale that parallels the Rosenberg (1989) global self-esteem scale $(\alpha=0.84)$. Statements like "You have a lot of good qualities" had response categories coded from 1 (strongly disagree) to 5 (strongly agree).

\section{Negative emotions}

Wave 1 of Add Health did not include specific measures of emotions that meet the time-ordering requirement of general strain theory. To assess negative emotions, five items from the "feelings scale" subsection of the Add Health were used to create a mean scale that tapped fear, anxiety, and depression. These items asked how often in the week prior to the interview that he or she experienced the negative feeling. Response categories for these items ranged from 0 (never) to 3 (most or all of the time). The items were: you felt fearful; you were bothered by things that usually don't bother you; you felt that you couldn't shake off the blues; you felt depressed; and, you felt sad. These items loaded on a single factor, were highly intercorrelated $(p<0.001)$, and had an alpha reliability score of 0.79 . The structure of these three items alleviated some concern regarding time-ordering of the victimization experience and feeling negative emotions. That is, it is more likely that the victimization experience occurred prior to or concurrent with reporting on these emotions, rather than the victimization experience occurring after the onset of reported emotions.

\section{Variables controlling for competing theories}

Three control variables that represent competing theoretical explanations were included in the regression models. First, to tap a portion of what Agnew, Brezina, Wright, and Cullen (2002) termed "negative emotionality/low constraint," temper was measured with one item that asked the parent if the adolescent had a bad temper, coded 0 for no and 1 for yes. Second, a curfew variable was used to represent the opportunity for engaging in delinquency. This was measured with one item asking whether the respondent was allowed to make his or her own decision about weekend curfew. The responses were coded 0 for no and 1 for yes. Third, the analyses included a variable to represent the effect of involvement with delinquent peers. This was measured with one item that asked respondents how many times in the past twelve months they had engaged in a group fight with their friends against another group. The responses were dichotomized so that 0 indicated the respondent had not engaged in a group fight, and 1 indicated that he or she had done so at least once. All of these items were assessed at Wave 1. Finally, the Wave 1 measure of general delinquency was included in each model as a statistical control against potential selection effects.

\section{Demographic control variables}

Other control variables include age, race, sex, socio-economic status, and family structure. Race was a dummy variable where White was the reference group, and the categories were Black, Hispanic, and other. Sex was a dummy variable, where female was the reference group. Household socio-economic status, described in the Wave 1 parent interview, was measured by the highest level of education completed by an adult in the household, ranging from less than high school to a professional or graduate degree. Family structure, described by adolescent at Wave 2, was a dummy variable where twoparent household served as the reference group.

\section{Analysis plan}

All statistical tests that involved estimates of the mean and regression estimates incorporated the weighting techniques advised by Chantala and Tabor (1999). As with much delinquency research, the initial general delinquency and violent delinquency scales had a large number of zero values and a positive skew. To manage the skew of these variables, response categories were collapsed and then dichotomized. For violent delinquency, responses were coded zero if the adolescent had engaged in no violent act and coded one if the adolescent had engaged in one or more of any type of the three acts included on the initial measure. The same procedure was followed for the property delinquency and nuisance delinquency categories, as well as the selling drugs and running away items. Finally, the general delinquency measure used in the analyses consisted of the sum of the dichotomized violent delinquency, property delinquency, nuisance delinquency, selling drugs, and running away variables. Thus, the general delinquency scale ranged from zero to five, with a mean of 1.03 and skew value of 1.03 .

Pearson's correlations (two-tailed) among the victimization variables were assessed. Correlation analyses indicated a strong correlation between experienced and witnessed victimization $(r=0.43, p<0.001)$, and weaker correlations among experienced victimization and anticipated victimization variables $(r<0.17, p<0.001)$, and witnessed victimization and anticipated victimization variables $(r<0.15, p<0.001)$. There were also significant correlations among the anticipated victimization items, particularly between perceptions of school and neighborhood safety $(r=0.22, p<0.001)$. To avoid misspecification of the models, all forms of victimization were included together in the regression models (Agnew, 2002).

Table I. Descriptive statistics

\begin{tabular}{lccc}
\hline Variables & Mean or \% & Std. dev. & Range \\
\hline Age & 15.98 & 1.54 & $\mid \mathrm{II-2I}$ \\
Hispanic & 14.52 & & \\
Black & 20.42 & & \\
Other race & 7.42 & & \\
Sex (female = 0) & 51.63 & & \\
Household education & 4.00 & 1.30 & $0-6$ \\
Family structure (two-parent $=0$ ) & 72.15 & & \\
Experienced victimization & 0.23 & 0.42 & $0-1$ \\
Witnessed victimization & 0.11 & 0.31 & $0-1$ \\
Killed by age twenty-one & 0.14 & 0.35 & $0-1$ \\
School unsafe & 0.13 & 0.33 & $0-1$ \\
Neighborhood unsafe & 0.10 & 0.30 & $0-1$ \\
Negative emotions & 0.43 & 0.49 & $0-3$ \\
Temper & 0.29 & 0.45 & $0-1$ \\
Group fight w/ peers & 0.20 & 0.40 & $0-1$ \\
Curfew & 0.29 & 0.45 & $0-1$ \\
General delinquency (wave I) & 1.34 & 1.22 & $0-5$ \\
General delinquency (wave 2) & 1.03 & 1.13 & $0-5$ \\
Violent delinquency (wave 2) & 0.20 & 0.40 & $0-1$ \\
\hline
\end{tabular}


Table 2. OLS regressions predicting negative emotions by resource groups

\begin{tabular}{|c|c|c|c|c|c|c|}
\hline Variables & $\begin{array}{l}\text { Low } \\
\text { social } \\
\text { support } \\
n=5543\end{array}$ & $\begin{array}{l}\text { High } \\
\text { social } \\
\text { support } \\
n=4861\end{array}$ & $\begin{array}{l}\text { Low } \\
\text { self- } \\
\text { esteem } \\
n=4861\end{array}$ & $\begin{array}{l}\text { High } \\
\text { self- } \\
\text { esteem } \\
n=5226\end{array}$ & $\begin{array}{l}\text { Low } \\
\text { resources } \\
n=3377\end{array}$ & $\begin{array}{l}\text { High } \\
\text { resources } \\
n=3060\end{array}$ \\
\hline $\begin{array}{l}\text { Experienced } \\
\text { vic. }\end{array}$ & $\begin{array}{l}0.14 \text { *** } \\
(0.02) \\
0.12\end{array}$ & $\begin{array}{l}0.12 \text { **** } \\
(0.02) \\
0.11\end{array}$ & $\begin{array}{l}0.15 * * * \\
(0.03) \\
0.13\end{array}$ & $\begin{array}{l}0.11 \text { *** } \\
(0.02) \\
0.10\end{array}$ & $\begin{array}{l}0.14 * * * \\
(0.03) \\
0.13\end{array}$ & $\begin{array}{l}0.12 \text { ***** } \\
(0.03) \\
0.10\end{array}$ \\
\hline $\begin{array}{l}\text { Witnessed } \\
\text { vic. }\end{array}$ & $\begin{array}{c}0.08 * \\
(0.03) \\
0.05\end{array}$ & $\begin{array}{c}0.07 \\
(0.04) \\
0.04\end{array}$ & $\begin{array}{c}0.06 * \\
(0.03) \\
0.04\end{array}$ & $\begin{array}{c}0.08 \text { ** } \\
(0.03) \\
0.05\end{array}$ & $\begin{array}{c}0.07 \\
(0.04) \\
0.04\end{array}$ & $\begin{array}{c}0.08 \\
(0.05) \\
0.05\end{array}$ \\
\hline $\begin{array}{l}\text { Killed by age } \\
\text { twenty-one }\end{array}$ & $\begin{array}{l}0.11 * * * \\
(0.03) \\
0.08\end{array}$ & $\begin{array}{l}0.08 \text { ** } \\
(0.03) \\
0.06\end{array}$ & $\begin{array}{c}0.08 * * \\
(0.03) \\
0.06\end{array}$ & $\begin{array}{l}0.12 \text { *** } \\
(0.02) \\
0.08\end{array}$ & $\begin{array}{c}0.10 \text { ** } \\
(0.03) \\
0.07\end{array}$ & $\begin{array}{l}0.11 \text { ** } \\
(0.04) \\
0.08\end{array}$ \\
\hline School unsafe & $\begin{array}{l}0.18 \text { *** } \\
(0.03) \\
0.12\end{array}$ & $\begin{array}{l}0.15 \text { **** } \\
(0.03) \\
0.10\end{array}$ & $\begin{array}{l}0.20 * * * \\
(0.03) \\
0.13\end{array}$ & $\begin{array}{l}0.13 \text { **** } \\
(0.03) \\
0.09\end{array}$ & $\begin{array}{c}0.19 * * * \\
(0.04) \\
0.13\end{array}$ & $\begin{array}{c}0.10 \text { ** } \\
(0.04) \\
0.07\end{array}$ \\
\hline $\begin{array}{l}\text { Neighbor- } \\
\text { hood unsafe }\end{array}$ & $\begin{array}{c}0.10 \text { ** } \\
(0.03) \\
0.06\end{array}$ & $\begin{array}{c}0.08 * \\
(0.03) \\
0.05\end{array}$ & $\begin{array}{c}0.12 \text { ** } \\
(0.04) \\
0.07\end{array}$ & $\begin{array}{c}0.04 \\
(0.03) \\
0.03\end{array}$ & $\begin{array}{c}0.11 * \\
(0.05) \\
0.07\end{array}$ & $\begin{array}{c}0.05 \\
(0.04) \\
0.03\end{array}$ \\
\hline$R^{2}$ & 0.132 & 0.089 & 0.111 & 0.096 & 0.121 & 0.081 \\
\hline
\end{tabular}

Unstandardized coefficients with standard errors in parentheses and standardized coefficients in italics. The models included the demographic control variables (age, sex, race/ethnicity, education, family structure), which accounted for 5 to $7 \%$ of the variance.

a. The mid-level resources group $(n=3967)$ is excluded from the table.

$* * * p<.001 ; * * p<.01 ; * p<.05$ (two-tailed)
Given the challenges encountered by much GST research using multiplicative interaction terms to test conditional effects (Mazerolle \& Maahs, 2000), the analyses followed the approach used by Capowich et al. (2001), dividing the sample into groups. To create groups reflecting low social support versus high social support, the sample was divided at the median. The same procedure was used to create low versus high self-esteem groups. Additionally, social support and self-esteem were significantly correlated $(r=0.36, p<0.001)$. Groups were created to reflect adolescents who were low in both social support and self-esteem versus adolescents who were high in both. Those who were below the median in both support and self-esteem were categorized in the low resources group, and those above the median on both were categorized in the high resources group.

Regression analyses were then performed separately for each group. OLS regression procedures were used to determine the effect of victimization on negative emotions. Then, OLS regression procedures were used for general delinquency models, and logistic regression procedures were used for violent delinquency models. In each of these regression analyses, the control and victimization variables were modeled first (Model I); then, the negative emotions variable was entered into the models to detect potential mediating effects (Model II). General strain theory suggests that entering the negative emotions variable into the equations, if it mediates the relationship between victimization and delinquency, should reduce the impact of the victimization variables either substantially or to non-significance.

\section{Results}

Table 1 shows the descriptive information for the sample. To provide an initial examination of the relationships among the variables for the full sample, the control variables, victim-

Table 3. OLS regressions predicting general delinquency by social support and self-esteem groups

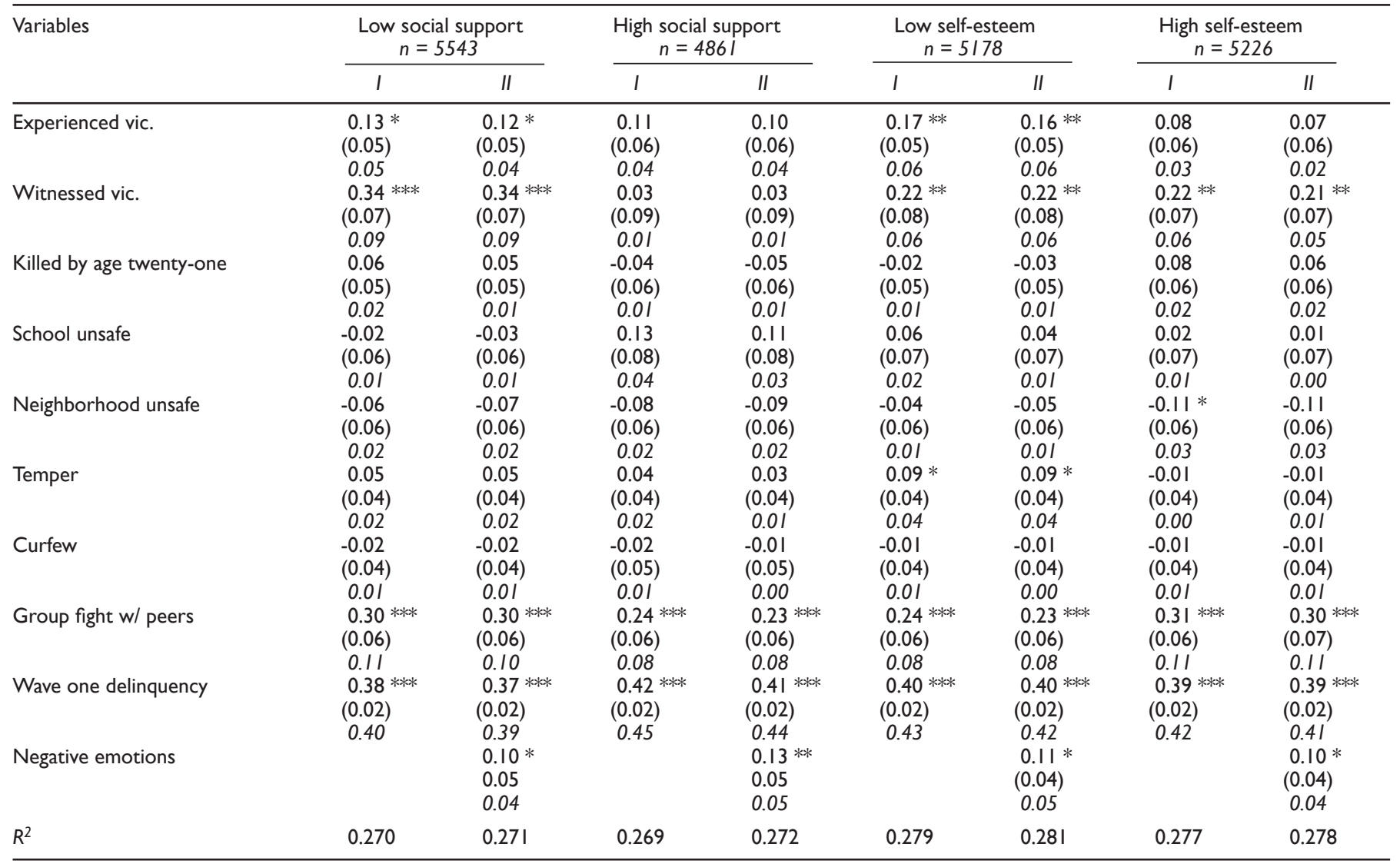

Unstandardized coefficients with standard errors in parentheses and standardized coefficients in italics. All models include the demographic control variables (age, sex, race/ethnicity, education, family structure), which accounted for 2 to $3 \%$ of the variance. *** $p<.001 ; * * p<.01 ; * p<.05$ (two-tailed). 
ization, and negative emotions were regressed on general delinquency. Several relationships significant at $p<0.05$ or less emerged. Age was negatively related to delinquency $(\beta=0.05)$, Black adolescents were less likely to engage in delinquency than White adolescents $(\beta=0.05)$, males were more likely to be delinquent than females $(\beta=0.04)$, and prior delinquency $(\beta=0.42)$ and peer delinquency $(\beta=0.09)$ were positively related to Wave Two delinquency. Adolescents who experienced victimization $(\beta=0.04)$ and adolescents who witnessed victimization $(\beta=0.06)$ were more likely to be delinquent. Negative emotions $(\beta=0.05)$ were positively related to general delinquency but did not mediate the effects of victimization. Additional models included social support, self-esteem, and resource groups as dummy variables. Adolescents in the high social support group $(\beta=0.04)$ and in the high self-esteem group $(\beta=0.03)$ were less likely to engage in general delinquency than those in the low groups. Adolescents in the midrange $(\beta=0.04)$ and high resources groups $(\beta=0.06)$ were less likely to be delinquent than those in the low resources group.

The control variables, victimization, negative emotions, and social support and self-esteem were also regressed on violent delinquency for the full sample. Several relationships significant at $p<0.05$ or less emerged. Age $(O R=0.91)$ and household education $(O R=0.91)$ were negatively related to violence, males were more likely to be violent than females $(O R=2.09)$, adolescents with bad tempers were more likely to be violent $(O R=1.32)$, and prior delinquency $(O R=1.56)$ and peer delinquency $(O R=1.91)$ were positively related to Wave Two violent delinquency. Adolescents who experienced victimization $(O R=1.55)$, those who witnessed victimization $(O R=1.73)$, and those who felt their neighborhoods were unsafe $(O R=1.24)$ were more likely to engage in violent delinquency. Negative emotions $(O R=1.21)$ predicted violent delinquency but did not mediate the effects of victimization. Additional models included social support, self-esteem, and resource groups as dummy variables. Adolescents in the high social support group were less likely to engage in violent delinquency than those in the low support group $(O R=0.83)$. For the full sample, self-esteem and resources were not significant predictors of violent delinquency.

To examine the relationship between victimization experiences and negative emotions, Table 2 presents the results for OLS regressions of the victimization variables on negative emotions for the social support and self-esteem groups. With a few exceptions, all of the victimization variables were positively related to feeling negative emotions. Witnessing victimization did not predict negative emotions in the high social support or high resources groups, and perceptions of neighborhood safety were not related to emotions in the high selfesteem and high resources groups. Although the measure was conservative, these findings were consistent with the GST premise that strain leads to negative emotional states.

To detect potential conditional effects, Table 3 presents the results for OLS regressions of victimization on general delinquency across social support and self-esteem groups. Among those with lower levels of social support, experiencing violent victimization and witnessing victimization significantly predicted general delinquency. In contrast, victimization was unrelated to delinquency among those with higher levels of social support. When negative emotions were entered into the model, there was no impact on the relationship between victimization and general delinquency. Although negative emotions were significantly related to delinquency in both social support groups, they did not mediate the effect of victimization.

Among those with lower levels of self-esteem, experiencing violent victimization and witnessing victimization significantly predicted general delinquency. Witnessing victimization also predicted delinquency in the high self-esteem group. In contrast, among those with higher levels of self-esteem, experiencing victimization was unrelated to delinquency and feeling the neighborhood was unsafe was negatively related to delinquency. For the low self-esteem group, those with a bad temper were more likely to engage in delinquency. Similar to the results for the social support groups, negative emotions were significantly related to delinquency in both self-esteem groups but did not mediate the effect of victimization.

Table 4 presents regression results for the sample divided into groups representing lower social support and self-esteem versus higher social support and self-esteem. A similar pattern emerged. Among those with lower levels of these resources, experiencing violent victimization and witnessing victimization significantly predicted general delinquency. In contrast, victimization was unrelated to delinquency among those with higher levels of resources. For the low resources group, adolescents with a bad temper were more likely to engage in delinquency. Although negative emotions were significantly related to delinquency in both low and high resources groups, the relationship between victimization and delinquency was not mediated by negative emotions.

Table 5 and Table 6 present the results for logistic regressions of victimization on violent delinquency across resource groups. Experiencing violent victimization had a significant effect on violent delinquency in every group. In no case were the coefficients between the low and high groups were significantly different from each other, as indicated by z-scores. Witnessing violent victimization had a significant effect on violent delinquency across self-esteem groups. Although not statistically different, the odds ratios indicated that a person with low self-esteem who witnessed victimization was 1.85 times

Table 4. OLS regressions predicting general delinquency by low and high resources groups ${ }^{\mathrm{a}}$

\begin{tabular}{|c|c|c|c|c|}
\hline \multirow[t]{2}{*}{ Variables } & \multicolumn{2}{|c|}{$\begin{array}{c}\text { Low resources } \\
n=3377\end{array}$} & \multicolumn{2}{|c|}{$\begin{array}{c}\text { High resources } \\
n=3060\end{array}$} \\
\hline & I & II & I & II \\
\hline Experienced vic. & $\begin{array}{c}0.19 \text { ** } \\
(0.06) \\
0.07\end{array}$ & $\begin{array}{c}0.18 \text { ** } \\
(0.06) \\
0.07\end{array}$ & $\begin{array}{c}0.11 \\
(0.07) \\
0.04\end{array}$ & $\begin{array}{c}0.10 \\
(0.07) \\
0.04\end{array}$ \\
\hline Witnessed vic. & $\begin{array}{l}0.35 * * * \\
(0.10) \\
0.09\end{array}$ & $\begin{array}{l}0.34 \text { *** } \\
(0.10) \\
0.09\end{array}$ & $\begin{array}{c}0.10 \\
(0.12) \\
0.03\end{array}$ & $\begin{array}{c}0.10 \\
(0.12) \\
0.03\end{array}$ \\
\hline Killed by age twenty-one & $\begin{array}{c}-0.02 \\
(0.07) \\
0.01\end{array}$ & $\begin{array}{c}-0.03 \\
(0.07) \\
0.01\end{array}$ & $\begin{array}{c}-0.04 \\
(0.07) \\
0.01\end{array}$ & $\begin{array}{c}-0.06 \\
(0.07) \\
0.02\end{array}$ \\
\hline School unsafe & $\begin{array}{c}0.01 \\
(0.08) \\
0.00\end{array}$ & $\begin{array}{c}-0.01 \\
(0.08) \\
0.00\end{array}$ & $\begin{array}{c}0.09 \\
(0.09) \\
0.03\end{array}$ & $\begin{array}{c}0.08 \\
(0.09) \\
0.02\end{array}$ \\
\hline Neighborhood unsafe & $\begin{array}{c}-0.04 \\
(0.08) \\
0.01\end{array}$ & $\begin{array}{c}-0.05 \\
(0.08) \\
0.01\end{array}$ & $\begin{array}{c}-0.11 \\
(0.07) \\
0.03\end{array}$ & $\begin{array}{c}-0.12 \\
(0.07) \\
0.03\end{array}$ \\
\hline Temper & $\begin{array}{c}0.10 * \\
(0.05) \\
0.04\end{array}$ & $\begin{array}{c}0.10 * \\
(0.05) \\
0.04\end{array}$ & $\begin{array}{c}0.02 \\
(0.05) \\
0.01\end{array}$ & $\begin{array}{c}0.02 \\
(0.05) \\
0.01\end{array}$ \\
\hline Curfew & $\begin{array}{c}-0.01 \\
(0.05) \\
0.00\end{array}$ & $\begin{array}{c}-0.01 \\
(0.05) \\
0.00\end{array}$ & $\begin{array}{c}-0.01 \\
(0.06) \\
0.01\end{array}$ & $\begin{array}{c}-0.01 \\
(0.06) \\
0.01\end{array}$ \\
\hline Group fight w/ peers & $\begin{array}{l}0.27 \text { *** } \\
(0.07) \\
0.10\end{array}$ & $\begin{array}{l}0.27 \text { *** } \\
(0.07) \\
0.09\end{array}$ & $\begin{array}{c}0.26 * * \\
(0.08) \\
0.09\end{array}$ & $\begin{array}{c}0.25 * * \\
(0.08) \\
0.09\end{array}$ \\
\hline Wave I delinquency & $\begin{array}{l}0.38 \text { *** } \\
(0.03) \\
0.40\end{array}$ & $\begin{array}{c}0.37 \text { *** } \\
(0.03) \\
0.39\end{array}$ & $\begin{array}{c}0.41 * * * \\
(0.02) \\
0.44\end{array}$ & $\begin{array}{l}0.40 \text { **** } \\
(0.02) \\
0.43\end{array}$ \\
\hline Negative emotions & & $\begin{array}{c}0.11 * \\
(0.05) \\
0.04\end{array}$ & & $\begin{array}{c}0.16^{* *} \\
(0.06) \\
0.07\end{array}$ \\
\hline$R^{2}$ & 0.276 & 0.279 & 0.280 & 0.283 \\
\hline
\end{tabular}

Unstandardized coefficients with standard errors in parentheses and standardized coefficients in italics. All models include the demographic control variables (age, sex, race/ethnicity, education, family structure), which accounted for 2 to $3 \%$ of the variance.

a. The mid-level resources group $(n=3967)$ is excluded from the table. $* * * p<.001 ; * * p<.01 ; * p<.05$ (two-tailed) 
Table 5. Logistic regressions predicting violent delinquency by social support and self-esteem groups

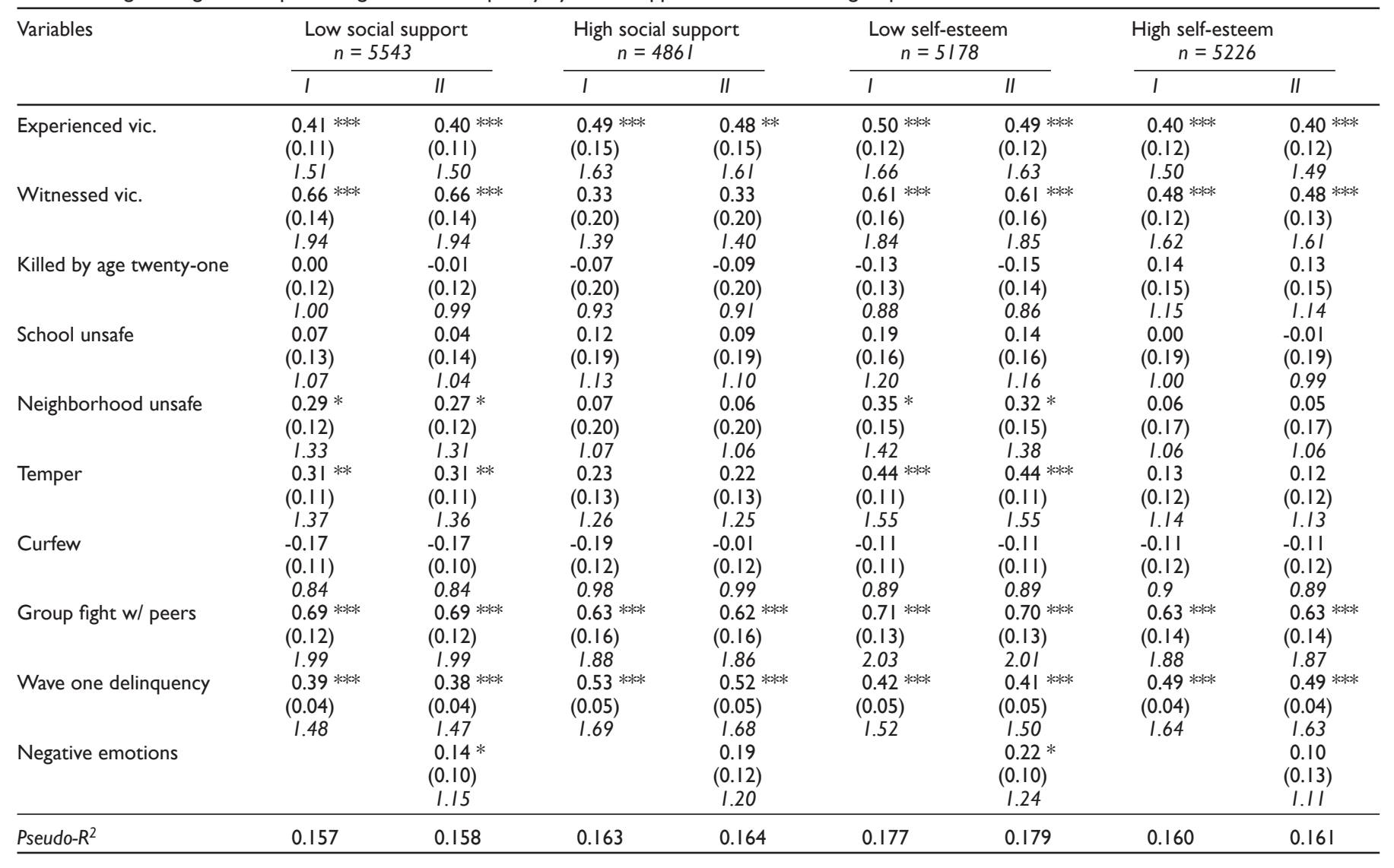

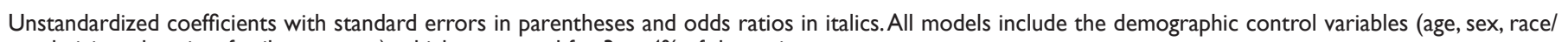
ethnicity, education, family structure), which accounted for 3 to $4 \%$ of the variance. $* * * p<.001 ; * * p<.01 ; * p<.05$ (two-tailed)

more likely to engage in violent delinquency, whereas a person with high self-esteem was 1.61 times more likely to engage in violence. Unlike the findings for the self-esteem groups, the effect of witnessing victimization was only significant in the low social support group and in the low resources group. In the low support group, the odds ratios indicated that a person who witnessed victimization was 1.94 times more likely to engage in violence. In the low resources group, a person who witnessed victimization was 2.12 times more likely to engage in violence. Perceiving the neighborhood to be unsafe had a significant effect on violent delinquency only in the low social support, low self-esteem, and low resources groups.

Interestingly, the effect of negative emotions on violent delinquency was significant only in the low social support, low self-esteem, and low resources groups. In these groups, entering negative emotions into the model only slightly reduced the impact of experienced victimization and perception of neighborhood safety on violent delinquency. There was no impact on the relationship between witnessing victimization and violence. Overall, the relationship between victimization and violent delinquency was not substantially mediated by negative emotions in any group. An additional result of note was the effect of a bad temper. Temper was significantly related to violent delinquency only in the low social support, low self-esteem, and low resources groups.

\section{Discussion}

The results reported here provide support for the GST proposition that personally experienced and vicarious victimization can be viewed as stressors that lead to delinquent outcomes. In support of Hypothesis 1, among adolescents, the experience of violent victimization, witnessing the violent victimization of others, and perceiving their neighborhood to be unsafe contributed to delinquency in general and violent delinquency in particular. Moreover, consistent with Hypothesis 3 , social support and self-esteem conditioned these relationships. For adolescents with high levels of these resources, experienced and witnessed victimization were unrelated to general delinquency. In contrast, for adolescents with low levels of these resources, experienced and witnessed victimization led to later delinquency.

The conditioning effects of social support and self-esteem were also documented for violent delinquency. For those adolescents with high levels of both these resources, witnessing victimization was unrelated to violent delinquency but led to violence for adolescents with low social support and with low levels of both resources. Likewise, perceiving their neighborhood to be unsafe led to later violent delinquency only for adolescents with low levels of social support and self-esteem. Agnew (2002) argued that witnessing victimization may prompt retaliation and that concern for one's safety may lead some to be proactive, acting out against others to prevent future victimization. In this study, such an effect was observed only for adolescents low in social support and self-esteem, supporting the notion that without these resources adolescents may be less able to find legitimate ways to cope, resorting to violent means. In contrast with the other evidence supporting Hypothesis 3, the conditioning effects of social support and self-esteem were not observed for experienced victimization and violent delinquency. When it comes to experienced victimization, these resources may help an individual cope well enough to avoid delinquency in general, but not successfully enough to avoid further violence. 
Table 6. Logistic regressions predicting violent delinquency by low and high resources groups ${ }^{\mathrm{a}}$

\begin{tabular}{|c|c|c|c|c|}
\hline \multirow[t]{2}{*}{ Variables } & \multicolumn{2}{|c|}{$\begin{array}{l}\text { Low resources } \\
\qquad n=3377\end{array}$} & \multicolumn{2}{|c|}{$\begin{array}{l}\text { High resources } \\
\quad n=3060\end{array}$} \\
\hline & I & II & I & II \\
\hline Experienced vic. & $\begin{array}{c}0.45 * * \\
(0.15) \\
1.58\end{array}$ & $\begin{array}{l}0.43 * * \\
(0.15) \\
I .54\end{array}$ & $\begin{array}{l}0.43 * * \\
(0.16) \\
1.54\end{array}$ & $\begin{array}{l}0.42 \text { ** } \\
(0.16) \\
1.52\end{array}$ \\
\hline Witnessed vic. & $\begin{array}{l}0.75 * * * \\
(0.19) \\
2.12\end{array}$ & $\begin{array}{l}0.75 * * * \\
(0.19) \\
2.12\end{array}$ & $\begin{array}{c}0.37 \\
(0.20) \\
1.45\end{array}$ & $\begin{array}{c}0.37 \\
(0.20) \\
1.45\end{array}$ \\
\hline Killed by age twenty-one & $\begin{array}{c}-0.12 \\
(0.16) \\
0.89\end{array}$ & $\begin{array}{c}-0.15 \\
(0.16) \\
0.86\end{array}$ & $\begin{array}{c}0.06 \\
(0.25) \\
I .07\end{array}$ & $\begin{array}{c}0.02 \\
(0.26) \\
1.02\end{array}$ \\
\hline School unsafe & $\begin{array}{c}0.07 \\
(0.19) \\
1.07\end{array}$ & $\begin{array}{c}0.02 \\
(0.19) \\
1.02\end{array}$ & $\begin{array}{c}-0.16 \\
(0.26) \\
0.85\end{array}$ & $\begin{array}{c}-0.19 \\
(0.26) \\
0.83\end{array}$ \\
\hline Neighborhood unsafe & $\begin{array}{c}0.40 * \\
(0.17) \\
1.49\end{array}$ & $\begin{array}{c}0.36 * \\
(0.18) \\
1.44\end{array}$ & $\begin{array}{c}-0.03 \\
(0.23) \\
0.97\end{array}$ & $\begin{array}{c}-0.04 \\
(0.23) \\
0.96\end{array}$ \\
\hline Temper & $\begin{array}{l}0.44 * * * \\
(0.13) \\
1.56\end{array}$ & $\begin{array}{l}0.45 * * * \\
(0.12) \\
1.57\end{array}$ & $\begin{array}{c}0.12 \\
(0.17) \\
1.13\end{array}$ & $\begin{array}{c}0.11 \\
(0.17) \\
1.12\end{array}$ \\
\hline Curfew & $\begin{array}{c}-0.07 \\
(0.14) \\
0.93\end{array}$ & $\begin{array}{c}-0.07 \\
(0.14) \\
0.93\end{array}$ & $\begin{array}{c}0.07 \\
(0.16) \\
1.07\end{array}$ & $\begin{array}{c}0.06 \\
(0.16) \\
1.07\end{array}$ \\
\hline Group fight w/ peers & $\begin{array}{l}0.81 * * * \\
(0.17) \\
2.24\end{array}$ & $\begin{array}{l}0.80 * * * \\
(0.16) \\
2.23\end{array}$ & $\begin{array}{l}0.75 * * * \\
(0.20) \\
2.12\end{array}$ & $\begin{array}{l}0.74 \text { *** } \\
(0.21) \\
2.09\end{array}$ \\
\hline Wave I delinquency & $\begin{array}{c}0.36 * * * \\
(0.06) \\
1.43\end{array}$ & $\begin{array}{l}0.35 * * * \\
(0.06) \\
I .4 I\end{array}$ & $\begin{array}{c}0.54 \text { *** } \\
(0.06) \\
I .7 I\end{array}$ & $\begin{array}{c}0.52 \text { *** } \\
(0.05) \\
1.69\end{array}$ \\
\hline Negative emotions & & $\begin{array}{c}0.26 * \\
(0.11) \\
1.30\end{array}$ & & $\begin{array}{c}0.30 \\
(0.16) \\
1.34\end{array}$ \\
\hline Pseudo- $R^{2}$ & 0.174 & 0.176 & 0.173 & 0.174 \\
\hline
\end{tabular}

Unstandardized coefficients with standard errors in parentheses and odds ratios in italics. All models include the demographic control variables (age, sex, race/ethnicity, education, family structure), which accounted for 3 to $4 \%$ of the variance.

a. The mid-level resources group $(n=3967)$ is excluded from the table.

$* * * p<.001 ; * * p<.01 ; * p<.05$ (two-tailed)

The mediating effects of negative emotions predicted in Hypothesis 2 were not observed in these analyses. Certainly, the emotions measured here, unlike anger, are not necessarily considered to be conducive to other-directed forms of delinquency, but nor were they negatively associated with delinquency, as Agnew (2006) implied. One potential explanation for the lack of mediation may be that the measure of negative emotions was limited and may not have fully represented the emotional state of the respondent. The items on the scale assessed general feelings but not necessarily feelings the respondent had as a result of victimization. It is also likely that victimization brings on a range of emotions that are not easily captured in survey research. To this extent, future research should consider qualitative reports of the emotional states adolescents experience as a result of personal and vicarious victimization.

On the other hand, the failure of negative emotions to mediate the relationship between strain and criminal outcomes has been noted in other research. Tittle et al. (2008) proposed that strain itself may be enough motivation for illegitimate responses, particularly if there is opportunity for such responses and if they seem advantageous. In other words, people are not necessarily coping with negative emotions, as suggested by GST, but coping directly with the experience of strain itself. Indeed, Brezina (1996) illustrated that strain and delinquency interacted, with delinquency reducing the impact of strain on negative emotions. Theoretically, if an individual has greater means of accessing legitimate resources, and views those as more advantageous, that person would be less likely to engage in crime and delinquency to deal with strain (Tittle et al., 2008). If this is the case, then improving adolescents conventional support networks and self-esteem, which may provide access to legitimate coping resources and make those seem more beneficial, is essential.

Like previous research, this study revealed that negative emotions play a complex part in the victimization-delinquency relationship. In the general delinquency models, negative emotions directly impacted delinquency regardless of resources. Further, any impact of victimization on delinquency in the high support and high resources group was entirely indirect via negative emotions. When it came to violent delinquency, there appeared to be an association between resources and negative emotions. For those with low levels of social support and self-esteem, negative emotions contributed to violent delinquency. Taken together, the results suggest that the effect of victimization on delinquency may be both direct and indirect through negative emotions, theoretically consistent with GST. Moreover, the kinds of emotions measured in this study may make adolescents apathetic about the consequences of their actions, as well as withdrawn from or disinterested in prosocial activities, which may be linked to delinquency (Obeidallah \& Earls, 1999). If this is the case, then victimization can be particularly detrimental for those already low in coping resources.

There appeared to be an association between resources and temper. For those with low levels of resources, a bad temper contributed to both general and violent delinquency. The measure of temper, a one-time dichotomous parent-reported item was crude, and as such it provided a very conservative estimate, but the finding is consistent with GST. GST suggests that higher levels of social support and self-esteem may help adolescents control their tempers, perhaps because they represent access to legitimate resolutions or because they act as social or self-controls. In a related estimation limitation, this study was not able to assess the potential mediating effect of anger, a key variable in GST. Add Health does not contain a measure for state anger (i.e., feelings of anger that are generated by situation or circumstance) that would be ideal for a test of GST. To the extent that adolescents who have a trait like "bad temper" are more likely to experience situational anger (Mazerolle et al., 2003; Mazerolle \& Piquero, 1998), the analyses presented here hinted that anger did not mediate the effect of victimization on violent delinquency. Instead, for those with low levels of resources, temper had an independent effect on violence. Future research should explore the role of both temperament and anger in the relationship between victimization and delinquency, especially in the context of other social psychological factors.

Although perceiving their neighborhood to be unsafe led to later violence for adolescents with low levels of resources, the other indicators of anticipated victimization were not significant predictors of general or violent delinquency. Agnew (2002) suggested that "anticipated strain may prompt both flight and fight" (p. 613). That is, safety concerns may lead some to retreat to safer environs and avoid public spaces where victimization is more likely, or it may lead some to be proactive in preventing future victimization. To the extent both of these are operating within a sample, an effect in either direction may be difficult to detect. The measures of anticipated strain used in this study were less than ideal, because they were single-item indicators. They also could not assess the perceived probability of victimization or whether the threat was immediate versus delayed, features Agnew (2002) listed as factors that affect the likelihood that anticipated victimization will result in delinquent response. Future research should consider more nuanced measures of anticipated victimization that capture the respondent's sense of the likelihood of being victimized. Additionally, safety concerns may be tied to particular domains, such that perceptions of school 
safety may contribute specifically to truancy and concern for one's personal safety may contribute to escapist behavior like substance use or suicide attempts. Future analyses should consider such relationships.

The results can provide insight for policy makers who are concerned about adolescent victimization and for professionals who are in contact with adolescents victimized by violence. Victimization can be viewed as a stressor that leads to deviant behavior, so that community efforts to reduce victimization, and thus the associated strain, may have the added effect of reducing delinquency (Hay \& Evans, 2006). In addition to research that demonstrates a relationship between adolescent victimization and a host of negative outcomes, violent victimization puts adolescents at risk for early transitions to adulthood, including teenage pregnancy and continued involvement in violence (Hagan \& Foster, 2001). Individual and community efforts should target not only adolescents who are personally victimized, but also those who witness violence in their communities. For adolescents who experience victimization directly or vicariously, assistance in developing positive social support networks and in boosting self-esteem may prevent delinquency in general and violent delinquency in particular, as well as reduce the risk for other negative outcomes.

Acknowledgments - This article uses data from Add Health (Udry, 2003), a program project designed by J. Richard Udry, Peter S. Bearman, and Kathleen Mullan Harris, and funded by a grant P01-HD31921 from the Eunice Kennedy Shriver National Institute of Child Health and Human Development, with cooperative funding from seventeen other agencies. Special acknowledgment is due Ronald R. Rindfuss and Barbara Entwisle for assistance in the original design. Persons interested in obtaining data files from Add Health should contact Add Health, Carolina Population Center, 123 West Franklin Street, Chapel Hill, North Carolina, 27516-2524 (addhealth@unc.edu).

\section{References}

Aceves, M. J., \& Cookston, J. T. (2007). Violent victimization, aggression, and parent-adolescent relations: Quality parenting as a buffer for violently victimized youth. Journal of Youth and Adolescence, 36, 635-647.

Agnew, R. (1992). Foundation for a general strain theory of crime and delinquency. Criminology, 30, 47-87.

Agnew, R. (2001). Building on the foundation of general strain theory: Specifying the types of strain most likely to lead to crime and delinquency. Journal of Research in Crime and Delinquency, 38, 319-361.

Agnew, R. (2002). Experienced, vicarious, and anticipated strain: An exploratory study on physical victimization and delinquency. Justice Quarterly, 19, 603-633.

Agnew, R. (2006). Pressured into crime: An overview of general strain theory. Los Angeles, CA: Roxbury.

Agnew, R., Brezina, T., Wright, J. P., \& Cullen, F. T. (2002). Strain, personality traits, and delinquency: Extending general strain theory. Criminology, 40, 73-92.

Agnew, R., \& White, H. R. (1992). An empirical test of general strain theory. Criminology, 30, 457-499.

Allison, K. R., Adalf, E. M., \& Mates, M. (1997). Life strain, coping, and substance use among high school students. Addiction Research, 5, 251-272.

Aseltine, R. H., Gore, S., \& Gordon, J. (2000). Life stress, anger and anxiety, and delinquency: An empirical test of general strain theory. Journal Health and Social Behavior, 41, 256-275.

Bao, W., Hass, A., \& Pi, Y. (2007). Life strain, coping, and delinquency in the People's Republic of China: An empirical test of general strain theory from a matching perspective in social support. International Journal of Offender Therapy and Comparative Criminology, 51, 9-24.
Baron, S. W. (2004). General strain, street youth, and crime: A test of Agnew's revised theory. Criminology, 42, 457-483.

Baron, S. W. (2007). Street youth, gender, financial strain, and crime: Exploring Broidy and Agnew's extension to general strain theory. Deviant Behavior, 28, 273-302.

Bearman, P. S., Jones, J., \& Udry, J. R. (2009). The National Longitudinal Study of Adolescent Health: Study design. Accessed November 11, 2009, from Add Health Website: http://www.cpc.unc. edu/projects/addhealth/design

Brezina, T. (1996). Adapting to strain: An examination of delinquent coping responses. Criminology, 34, 39-60.

Brezina, T. (1998). Adolescent maltreatment and delinquency: The question of intervening processes. Journal of Research in Crime and Delinquency, 35, 71-99.

Broidy, L. (2001). A test of general strain theory. Criminology, 39, 9-36.

Capowich, G. E., Mazerolle, P., \& Piquero, A. (2001). General strain theory, situational anger, and social networks: An assessment of conditioning influences. Journal of Criminal Justice, $29,445-461$.

Centers for Disease Control. (2010). WISQARS leading causes of death reports, 1999-2006. Accessed January 19, 2010, from http://webappa.cdc.gov/sasweb/ncipc/leadcaus10.html

Chantala, K., \& Tabor, J. (1999). Strategies to perform a design-based analysis using the Add Health data. Accessed August 27, 2002, from Add Health Website: http://www.cpc.unc.edu/projects/addhealth/data/using/guides/weight1.pdf

Cleary, S. D. (2000). Adolescent victimization and associated suicidal and violent behaviors. Adolescence, 35, 671-682.

Cuevas, C. A., Finkelhor, D., Turner, H. A., \& Omrod, R. K. (2007). Juvenile delinquency and victimization: A theoretical typology. Journal of Interpersonal Violence, 22, 1581-1602.

Cullen, F. T. (1994). Social support as an organizing concept for criminology. Justice Quarterly, 11, 527-559.

Cullen, F. T., Wright, J. P., \& Chamlin, M. B. (1999). Social support and social reform: A progressive crime control agenda. Crime and Delinquency, 45, 188-207.

Eitle, D., \& Turner, R. J. (2002). Exposure to community violence and young adult crime: The effects of witnessing violence, traumatic victimization, and other stressful life events. Journal of Research in Crime and Delinquency, 39, 214-237.

Fagan, A. A. (2003). The short- and long-term effects of adolescent violent victimization experienced within the family and community. Violence and Victims, 18, 445-459.

Fagan, A. A., \& Mazerolle, P. (2008). Repeat offending and repeat victimization: Assessing similarities and differences in psychosocial risk factors, Crime and Delinquency. Accessed October 7, 2009 from http://cad.sagepub.com/cgi/ rapidpdf/0011128708321322v1.pdf

Flannery, D. J., Singer, M. I., \& Webster, K. (2001). Violence exposure, psychological trauma, and suicide risk in a community sample of dangerously violent adolescents. Journal of the American Academy of Child and Adolescent Psychiatry, 40, 435-442.

Hagan, J., \& Foster, H. (2001). Youth violence and the end of adolescence. American Sociological Review, 66, 874-899.

Hay, C., \& Evans, M. M. (2006). Violent victimization and involvement in delinquency: Examining predictions from general strain theory. Journal of Criminal Justice, 34, 261-274.

Haynie, D. L., Pett, R. J., Maimon, D., \& Piquero, A. R. (2009). Exposure to violence in adolescence and precocious role exits. Journal of Youth and Adolescence, 38, 269-286.

Hoffman, J. P., \& Cerbone, F. G. (1999). Stressful life events and delinquency escalation in early adolescence. Criminology, 37, 343-373.

Hoffman, J. P., \& Miller, A. S. (1998). A latent variable analysis of general strain theory. Journal of Quantitative Criminology, 14, 83-110. 
Hollist, D. R., Hughes, L. A., \& Schaible, L. M. (2009). Adolescent maltreatment, negative emotion, and delinquency: An assessment of general strain theory and family-based strain. Journal of Criminal Justice, 37, 379-387.

Jang, S. J. (2007). Gender differences in strain, negative emotions, and coping behaviors: A general strain theory approach. Justice Quarterly, 24, 523-553.

Jang, S. J., \& Johnson, B. R. (2003). Strain, negative emotions, and deviant coping among African Americans: A test of general strain theory. Journal of Quantitative Criminology, 19, 80-105.

Lauritsen, J. L., Sampson, R. J., \& Laub, J. H. (1991). The link between offending and victimization among adolescents. Criminology, 29, 265-292.

Macmillan, R. (2001). Violence and the life course: The consequences of victimization for personal and social development. Annual Review of Sociology, 27, 1-22.

Mazerolle, P., Burton, V. S., Cullen, F. T., Evans, T. D., \& Payne, G. L. (2000). Strain, anger, and delinquent adaptations: Specifying general strain theory. Journal of Criminal Justice, 28, 89-101.

Mazerolle, P., Capowich, G. E., \& Piquero, A. (2003). Examining the links between strain, situational and dispositional anger, and crime: Further specifying and testing general strain theory. Youth and Society, 35, 131-157.

Mazerolle, P., \& Maahs, J. (2000). General strain and delinquency: An alternative examination of conditioning influences. Justice Quarterly, 17, 753-778.

Mazerolle, P., \& Piquero, A. (1998). Linking exposure to strain with anger: An investigation of deviant adaptations. Journal of Criminal Justice, 26, 195-211.

Menard, S. (2002). Short- and long-term consequences of adolescent victimization. Accessed March 23, 2008, from Office of Juvenile Justice and Delinquency Prevention Website: http://www. ncjrs.gov/pdffiles1/ojjdp/191210.pdf

Moon, B., Blurton, D., \& McCluskey, J. D. (2008). General strain theory and delinquency: Focusing on the influences of key strain characteristics on delinquency. Crime and Delinquency, 54, 582-613.

Morash, M., \& Moon, B. (2007). Gender differences in the effects of strain on the delinquency of South Korean youth. Youth and Society, 38, 300-321.

Moses, A. (1999). Exposure to violence, depression, and hostility in a sample of inner city high school youth. Journal of Adolescence, 22, 21-32.

Neff, J. L., \& Waite, D. E. (2007). Male versus female substance abuse patterns among incarcerated juvenile offenders: Comparing strain and social learning variables. Justice Quarterly, 24, 106-132.

Obeidallah, D. A., \& Earls, F. J. (1999). Adolescent girls: The role of depression in the development of delinquency. Accessed January 15, 2007, from National Institute of Justice Website: http://www. ncjrs.gov/pdffiles1/fs000244.pdf

Ostrowsky, M. K., \& Messner, S. F. (2005). Explaining crime for a young adult population: An application of general strain theory. Journal of Criminal Justice, 33, 463-476.

Patchin, J. W., Huebner, B. M., McCluskey, J. D., Varano, S. P., \& Bynum, T. S. (2006). Exposure to community violence and childhood delinquency. Crime and Delinquency, 52, 307-332.

Paternoster, R., \& Mazerolle, P. (1994). General strain theory and delinquency: A replication and extension. Journal of Research in Crime and Delinquency, 31, 235-263.

Pearlin, L. I. (1989). The sociological study of stress. Journal of Health and Social Behavior, 30, 241-256.

Piquero, N. L., \& Sealock, M. D. (2000). Generalized general strain theory: An examination of an offending population. Justice Quarterly, 17, 449-484.
Rand, M., \& Catalano, S. (2007). Criminal victimization, 2006. Retrieved June 18, 2008, from Bureau of Justice Statistics Website: http:/ / www.ojp.usdoj.gov/bjs/pub/pdf/cv06.pdf

Robbers, M. L. P. (2004). Revisiting the moderating effect of social support on strain: A gendered test. Sociological Inquiry, 74, 546-569.

Rosenberg, M. (1989). Society and the adolescent self-image. Middletown, CT: Wesleyan University Press.

Rosenthal, B. S. (2000). Exposure to community violence in adolescence: Trauma symptoms. Adolescence, 35, 271-284.

Schwab-Stone, M. E., Ayers, T. S., Kasprow, W., Voyce, C., Barone, C., Shiver, T., et al. (1995). No safe haven: A study of violence exposure in an urban community. Journal of the American Academy of Child and Adolescent Psychiatry, 34, 215-224.

Schwab-Stone, M. E., Chen, C., Greenberger, E., Silver, D., Lichtman, J., \& Voyce, C. (1999). No safe haven II: The effects of violence exposure on urban youth. Journal of the American Academy of Child and Adolescent Psychiatry, 38, 359-367.

Shaffer, J. N., \& Ruback, R. B. (2002). Violent victimization as a risk factor for violent offending among juveniles. Accessed June 8, 2008, from Office of Juvenile Justice and Delinquency Prevention Website: http://www.ncjrs.org/pdffiles1/ojjdp/195737.pdf

Singer, M. I., Anglin, T. M., Song, L. Y., \& Lunghofer, L. (1995). Adolescents' exposure to violence and associated symptoms of psychological trauma. Journal of the American Medical Association, 273, 477-482.

Snyder, H. N., \& Sickmund, M. (2006). Juvenile offenders and victims: 2006 national report. Accessed January 23, 2008, from Office of Juvenile Justice and Delinquency Prevention Website: http:/ / ojjdp.ncjrs.gov/ojstatbb/nr2006/downloads/NR2006. pdf

Thoits, P. A. (1995). Stress, coping, and social support processes: Where are we? What next? [Special issue]. Journal of Health and Social Behavior, 53-79.

Tittle, C. R., Broidy, L. M., \& Gertz, M. G. (2008). Strain, crime, and contingencies. Justice Quarterly, 25, 283-312.

Turner, H. A., Finkelhor, D., \& Ormrod, R. (2006). The effect of lifetime victimization on the mental health of children and adolescents. Social Science and Medicine, 62, 13-27.

Turner, R. J., \& Lloyd, D. A. (1999). The stress process and the social distribution of depression. Journal of Health and Social Behavior, 40, 374-404.

Turner, R. J., \& Roszell, P. (1994). Psychosocial resources and the stress process. In W. R. Avison \& I. H. Gotlib (Eds.), Stress and mental health: Contemporary issues and prospects for the future (pp. 179-210). New York: Plenum Press.

Turner, R. J., \& Turner, J. B. (1999). Social integration and social support. In C. Aneshensel \& J. Phelan (Eds.), Handbook of the sociology of mental health (pp. 301-320). New York: Kluwer Academic/Plenum.

Udry, J. R. (2003). The National Longitudinal Study of Adolescent Health (Add Health), waves I \& II, 1994-1996 (Data file). Chapel Hill, NC: University of North Carolina, Carolina Population Center.

Udry, J. R. (2004). References, instruments, and questionnaires consulted in the development of the Add Health in-home adolescent interview. Accessed September 26, 2004, from Add Health Website: http://www.cpc.unc.edu/projects/addhealth/files/refer. pdf

Widom, C. S. (1989). Does violence beget violence? A critical examination of the literature. Psychological Bulletin, 106, 3-28. 